\title{
Something More: Moments of Meeting and the Teacher-Learner Relationship
}

\author{
Richard G. Tiberius \\ John Teshima \\ Alan R. Kindler \\ University of Toronto
}

The Boston Group, drawing upon developmental and clinical research, has identified special moments in human interaction that they call "moments of meeting. "These moments occur spontaneously within the context of ongoing relational interaction and can effectively restructure relationships. We think of these moments of meeting as pivotal moments because of their potentially pivotal effect on relationships. In this chapter we briefly describe the theory underlying these moments of relational change, using examples from education. Then we suggest strategies that may help teachers participate creatively in such moments. Finally, we explore the implications of this theory for the concept of authenticity.

\section{INTRODUCTION}

$\mathrm{F}$ ducators have come to appreciate the powerful role of the teacher-learner Erelationship in facilitating learning. Indeed, Joseph Lowman (1984) concludes that the teacher-learner relationship is as important to the facilitation of learning as are the traditional skills of the trade such as clarity of expression and organization. Until recently, the process of building and maintaining teacher-learner relationships has been understood as a gradual process of building an alliance through trust, a safe environment, and negotiation (Tiberius \& Billson, 1991). 
Recently, a group made up of psychiatrists, psychoanalysts, child development researchers, and pediatricians has been studying the process of change in normal development and, by analogy, in psychoanalytic or psychotherapeutic treatment. Working within that frame of reference, this group has described what they call "something more" than the traditional intervention of interpretation, which may be effective in contributing to the change process. They describe a process of change that occurs in the interactive relational domain, rather than in the domain of verbal and cognitive transactions, a process of relational restructuring that goes beyond the accepted one.

The elements of this new process are sudden, spontaneous, and dramatic in their impact. These moments of change are located in the microscopic study of the interaction between the patient and therapist. The Boston Group (Stern et al., 1998), drawing upon developmental and clinical research, has identified special moments in human interaction that they call "now moments." These moments occur spontaneously within the context of ongoing relational interaction and can lead to significant restructuring of relationships. From discussions with dozens of teachers, we are convinced that such moments also occur within the teacher-learner relationship. Whether these now moments lead to positive or negative restructuring of the relationship, or are just missed and have no impact whatsoever, depends largely on the ability of the teacher to seize-to authentically and personally respond to- these opportunities. The work of the Boston Group, therefore, suggests a mode of action through which teachers' authentic responsiveness in teacher-learner relationships may contribute positively to the learning process.

In this chapter we briefly describe the theory underlying these now moments, using examples from education. Then we explore the implications of this theory for the concept of authenticity as it is used in the higher education literature today. To anticipate our conclusion, authentic responses by teachers to now moments can have a powerful positive effect on the teacher-learner relationship-but at the price of increasing the teacher's vulnerability. We describe some exercises, taken from improvisational theater and meditation, aimed at enhancing our ability to recognize now moments and respond to them in ways that enhance the teacher-learner relationship. We also consider the risks faced by the teacher in such interactions, including the sense of increased vulnerability associated with exposure of his or her authentic self. Finally, using Parker Palmer's (1998) language, we explain the tension between the attraction of authenticity and the fear of vulnerability. 


\section{Present Moments, Now Moments, and Moments of Meeting}

A relationship can be understood as an ongoing process of mutual regulation toward some kind of inter-subjective goal. Relationship building is a trial and error process of negotiating, readjusting, and correcting, a process that Stern et al. (1998) call "moving along" (p. 909). Moving along consists of a string of present moments (see below) in which the participants interact as they attempt to fulfill the mutual goals of the relationship. These goals may range in complexity from the mundane, such as explaining the time and place of the next meeting, to the abstract and complex negotiation of intimacy.

When a present moment becomes emotionally "hot," it is a "now moment." We can recognize a now moment because it feels different from those that have gone before. This different quality may include positive feelings of increased intensity, excitement, and curiosity, or negative feelings of increased anxiety weirdness, or uncertainty. In other words, the minute you start to sweat in a teaching relationship, you have likely hit a now moment. Such interactive moments, whether colored by positive or negative affective tone, demand a unique and often personal response. If this moment is seized, that is, authentically and personally responded to by each person, it becomes a moment of meeting. The Boston Group's proposals suggest that these moments of meeting contribute to changes in the deeper relationship between teacher and student, changes that we believe may, in turn, positively affect the learning process. The Boston Group suggests that following such moments of meeting, a transient "disjoin" occurs between the two participants, an open space which allows new rules about how to be together to be creatively constructed between the pair. These new rules allow for a new kind of relationship to go forward, with unpredictable but often mutually rewarding consequences.

We will use two examples to illustrate the application of this theory. In the first one the teacher failed to seize a now moment and in the second the teacher succeeded and created a moment of meeting. Although the examples are from medical teaching, similar scenarios are common to any subject area.

\section{Example 1: Failure to Seize a Now Moment}

[Scene: An attending physician-teacher $(T)$ and medical student $(S)$ are talking directly after the student has seen a patient.]

Present moment T: So the patient is jaundiced? What are the causes of jaundice?

Present moment S: Gallstones? 
Present moment

Present moment

Present moment

Now moment

Failing response

Present moment
T: Yes, gallstones. And what is the mechanism behind gallstones causing jaundice?

S: Could be a problem with the biliary tract.

T: A problem with the biliary tract? What kind of problem?

S: [Smiling slightly, with a playful look.] Are you playing the game "Guess what's on my mind"?

T: [Staring coldly] I'm not playing any games. I'm teaching. In fact, I'm using the Socratic technique, one of the most effective teaching strategies in medical education.

S: [Subdued; continues answering the questions without enthusiasm.] Yes, well, maybe some kind of blockage of the biliary tract?

The above example illustrates the normal process of interaction, which is made up of a string of so-called present moments. Present moments occur within a framework defined by the nature of the relationship between this teacher and learner, and by the technique that the teacher is using. The Socratic technique required the teacher to ask questions and the student to answer them. This exchange moved along routinely until the student departed from the rules of taking turns (questions from the teacher followed by answers from the student) by asking a question ("Are you playing the game 'Guess what's on my mind'?"). With that question the student provoked a special kind of present moment, one that signaled a challenge to the familiar teaching strategy and to rules of the current teacher-student relationship. The dyad was pulled into the present, creating a now moment that was too specific and personal to be handled by a standard teaching strategy or script. Now moments force the teacher to change in some way, to improvise, usually with a novel response with respect to their previous relationship. If the teacher is able to do this, if he or she recognizes and seizes the now moment, it can lead to a moment of meeting which could expand his or her relationship (c.g., decpen the trust, increase the safety, etc.) with the student.

In the case described above, the teacher's response was more likely to constrict than to expand the relationship. The teacher's response clearly told the student that challenges to the teaching method were not allowed and that humor was not appreciated in this teacher-student relationship. The student 
felt chastised and became resigned to playing out this game in a mechanical fashion, according to the old rules. In the future, this student would be less likely to engage openly with this teacher, and their relationship might stagnate. As a consequence, learning would be stifled rather than facilitated.

\section{Example 2: Success in Seizing a Now Moment}

Present moment T: So the patient is jaundiced? What are the causes of jaundice?

Present moment S: Gallstones?

Present moment T: Yes, gallstones. And what is the mechanism behind gallstones causing jaundice?

Present moment S: Could be a problem with the biliary tract.

Present moment T: A problem with the biliary tract? What kind of problem?

Now moment S: [Smiling slightly] Are you playing the game "Guess what's on my mind"?

Seizing the moment $T$ : [Laughing, slapping hand on face.] Uhh... yeah, you got me! Guilty as charged. Was it that obvious? But I had noble intentions. I was trying to use the Socratic technique where I ask you questions to lead you to the answer instead of telling you the answer. I am told that it's a superior strategy to just telling students the answers. Doesn't it work for you?

Moment of meeting S: Well, maybe, but it makes me feel foolish. Like I really can't think. I have to follow the breadcrumbs that you're laying down. I don't want to just listen passively. That's no good either. It wouldn't stay with me.

Moment of meeting T: I hadn't thought of it that way. I can see how my method could drive you a bit mad. How about if 1 just ask you to tell me what you know about obstructive jaundice and then I'll give it a critique. And if that's not useful let's change it again. Don't be afraid to speak up. It's your education.

Moment of meeting S: That's a phrase I haven't heard very often. 
In this second example, the teacher responded to the student in a spontaneous and authentic way. In doing so, the teacher and student both now realize that 1) "It's okay to joke around in a teaching session" and 2) "It's okay for the student to question the teaching method." More fundamental is the realization that "It's okay to bring my own discomfort into the discussion and expect my teacher to be interested and responsive." As a result, the teacher-student relationship has been expanded in that both know more about each other's experience of the relationship. The teacher and student also know implicitly, in a way that may not available to verbal description, that they can relate to each other in new ways, ways that can allow the student to learn more effectively.

The exciting possible outcome of a moment of meeting is the expansion of the inter-subjective space. That is, the implicit teacher-student relationship temporarily loses its constraints-its hitherto unspoken and unrecognized rules-and is able to expand to accommodate a greater range of possibilities. Future interaction takes place within this context of these expanded possibilities (Stern et al., 1998). How can a moment of meeting precipitate such a sudden and dramatic change in the relationship? The Boston Group rely on nonlinear systems theory to conceptualize these events. The self-organizing feature of our minds tends to create progressively coherent relational knowledge from each relational experience throughout life. We bring these assumptions and expectations with us to each new relationship and the two new systems shape each other and organize a set of expectations or implicit knowledge of how it is to be with each other, in the context of our current goals. Each moment of meeting precipitates a process of shaping interpersonal knowledge about the other. The result is a modification of each relational partner's implicit relational knowledge of the other person. With each shift in the implicit rules of the relationship, new and unpredictable possibilities emerge and new relational systems are created.

The following features summarize the essential characteristics of a moment of meeting (Stern et al., 1998, p. 913):

- They are novel happenings, the opposite of business as usual

- They require a personal, specific response, not a routine, technical response

- They require spontaneity and improvisation; they cannot be planned or scripted 
- They have affective qualities which may include heightened intensity, discomfort excitement, arousal, strangeness, or disorientation - they deal with something important and different than business as usual happening now in the relationship between two people

- They need not be verbally explicated

- They are unique and cannot be repeated. They are not "tricks of the trade" that can be used in other situations with other people

- They require a sensibility, namely to be able to allow oneself to respond in a personal and spontaneous manner

\section{Enhancing the Ability to Create Moments of Meeting}

When we presented these ideas at workshops (at the annual meetings of POD and the Association of Academic Psychiatrists), participants found them gripping. Most of the participants easily identified situations in their teaching that were emotional, weird, uncomfortable, and difficult. They also had no trouble confirming the findings from the therapeutic literature regarding the powerful effects of these moments on their subsequent relationship with students. Virtually all participants were eager to learn how to respond constructively to such moments-to seize the moments, using the language of the theorists. We introduced three training methods that are particularly suited to this task.

The first of these methods borrows from the theatrical discipline of improvisation. Originally intended for actors, these skills assist teachers to develop flexibility and spontaneity in their roles. To respond constructively within a now moment the teacher may need to expand beyond his or her usual role responsiveness. Now moments require unique responses that are not formulaic but are constructed spontaneously to fit the specific situation. The ability to engage in a spontaneous response, to be in the moment, is precisely what improvisational theater is about. Our belief is that training in improvisational theater skills can enhance our ability to respond constructively at these unpredictable moments in the course of teaching.

Of course, teaching strategies are also essential to effective teaching. Irby (1994) has described "scripts" as mini teaching packages that comprise the best strategy to use in a situation defined by a particular teaching situation. Scripts help teachers become both effective and efficient. We, on the other hand, are arguing that sometimes teachers must be able to depart from their familiar scripts or their usual roles, in order to participate in these now moments effectively. This is especially true when the teacher is inclined to enact 
roles that are protective of the teacher's self-esteem or defensive of teachers' power and authority. Such teachers are more likely to miss the opportunities offered by now moments when they arise. Improvisational theater allows people to practice being spontaneous enough so that they overcome their fear of being vulnerable, of screwing up in front of the other person. It is all about an experiential process of developing the confidence to follow instincts, not technique. Our objective in providing practice in improvisational theater is to enhance the teachers' ability to be in the moment, to be flexible, to temporarily suspend their teaching strategies or their rules about their relationship with the student in order to enter into an authentic, personal interaction.

The second of these methods is mindfulness training (e.g., Kabat-Zinn, 1990 ). Mindfulness training may have an equally promising role to play in helping teachers seize now moments. Mindfulness training helps us preempt stereotypic responses like deeply ingrained teacher roles or habits. Such stereotypic responses prevent us from noticing the opportunity afforded by a now moment. Mindfulness releases a person's attention from captivity by these habitual thought trains. The objective of mindfulness training is not the development of automatic reflexes but something more like giving yourself the psychological space to make a decision based upon self-reflection, knowing when to allow yourself to step out of role and follow your instincts. This is the key point. Both mindfulness training and improvisational theater should provide teachers with increased confidence and the readiness to be spontaneous and authentic. Seizing the moment requires a kind of sensitivity to the subjective qualities of relational events rather than a skill brought objectively to bear on a specific situation.

A third method we would suggest, extrapolated from Teasdale, Segal, and Williams's (1995) clinical work on attention control training of consists of practicing new trigger responses to compete with habitual ones. Assume that our first Socratic teacher, while rushing to class, had an angry altercation with another driver in the parking lot, who chucked the finger at him. He was primed for anger. The student who challenged his teaching method may have been the final straw. This teacher could make up positive responses and practice them in situations in which unhelpful reflexes are provoked. For our Socratic teacher, these situations may be ones in which students challenge him. He needs new trigger responses. An analogy given by Teasdale, Segal, and Williams (1995, p. 32) is as follows: Most people would complete MOU_with SE. But this tendency can be reversed by presentations of the word MOUND. The object of this practice is to raise the likelihood that you will complete the pattern that begins with an emotional trigger in a different way. 
Teachers would need to practice the new patterns on many occasions, in many different contexts.

\section{Fear of Responding in an Authentic Manner}

Although the most common reaction to our workshops was eagerness to learn strategies for seizing now moments, the second most common reaction was apprehension. Participants expressed their fear of becoming vulnerable should they become more authentic in their responses. Some of the workshop participants had hoped that improvisational theater would provide them with a means of acquiring lightning quick reflexes that they could call upon in psychologically perilous situations. They were looking for the teacher's equivalent of martial arts training — skills that would protect them from attack by their students.

We have been impressed with the intensity of the fear expressed by participants each time we have presented these ideas to a group. One participant told us that the teacher role is protective. He feels safe while he is in the role of authority, talking about the subject without disclosing his own personal attitudes or weaknesses. Disclosures of a personal nature may invite reciprocation by the student. Boundary issues lie in this direction, he pointed out. He was not prepared to engage in a conversation with a student concerning his private life, his real beliefs about the subject, or his weaknesses. Yet, all of these interactions that invoke his vulnerability are also authentic interactions according to the educational literature.

Honesty about what one knows, for example, is one of the central characteristics of authenticity. A teacher who does not know something about a subject and admits it publicly is authentic. Another characteristic of an authentic response to students is "integrity" (Brookfield, 1990, p. 164), the congruence between a teacher's words and actions. A third is the teacher's connection with the subject matter that the student is trying to learn. It is essential that teachers reveal to students their actual connection to the subject, including their emotional responses to it. Authentic teachers, according to Chickering and Reisser (1993), have a well-integrated system of values and behaviors of their own, but they do not impose them on the learners. They disclose the basis of their beliefs and values so that the learners can reflect on their choices and make their own decisions. Finally, authentic teachers respect learners by hearing their personal concerns and by receptivity to learners' ideas (Brookfield, 1990). These types of responses put the teacher at psychological risk.

Parker Palmer (1998), in his enormously popular book, The Courage to Teach, analyzed the fear that paralyzes authentic teaching. One of the deepest 
human fears, he writes, is the fear of a live encounter with what he calls "alien otherness" (Palmer, 1998, p. 37). The "other" can be a student who speaks her or his own truth, telling us what we may not want to hear and threatening our view of the world or self - as in our example: "Are you playing the game 'Guess what's on my mind'?" Palmer (1998) argues that we rather control the outcomes of encounters with students. He goes on to describe various teaching roles that insolate teachers from confrontation with such live encounters: hiding behind notebooks, podiums, credentials, power, the pretence of objectivity, or silence (Palmer, 1998). Teaching requires an act of courage because teachers expose themselves in very personal ways-they are vulnerable (Palmer, 1998).

In her book, Teaching to Transgress: Education as the Practice of Freedom, bell hooks (1994) addresses similar themes. She states that she was helped the most by teachers "who have had the courage to transgress those boundaries that would confine each pupil to a rote, assembly-line approach to learning" (hooks, 1994, p.13). She argues that teachers should not operate in a position of safery and power and encourages them to bring their own personal experiences into teaching situations (hooks, 1994). She emphasizes that teachers must be willing to take the same personal risks that they expect of their students-they need to be able to "practice being vulnerable in the classroom" (hooks, 1994, p. 21).

\section{Inducing the Creative Tension}

We have begun to appreciate a conflict inherent in these moments of meeting. The joy of the moments of meeting was as palpable as the fear. When participants at our workshops spoke about their moments of meeting, they were excited. They were not driven to engage in moments of meeting out of some theoretical obligation to authentic teaching; they were drawn to the moments. They got an emotional jag, a kind of high, from expanding their relationship with their students. The expansion of a relationship is exciting. It's like seeing something in a new light, a brighter light. The romantic literature is full of this kind of imagery, of course, but the same phenomenon happens in other areas such as appreciation of art, music, the natural world, or, as we are observing, in the world of teacher-student relationships. This is the positive pole. The negative pole, as we discussed above, is fear.

The two conflicting motivations create what Parker Palmer (1998) has called a paradoxical tension, the creative tension that exists within each of the dimensions of a successful teacher-learner relationship. This tension is not 
something to avoid or eliminate. It is one of the characteristics of effective teaching. In Parker Palmer's (1998) words:

Teaching and learning require a higher degree of awareness than we ordinarily possess - and awareness is always heightened when we are caught in a creative tension. Paradox is another name for that tension, a way of holding opposites together that creates an electric charge that keeps us awake. Not all good teachers use the same technique, but whatever technique they use, good teachers always find ways to induce this creative tension. (pp. 73-74)

Creative tension is a good thing, but debilitating conflict is not. Some of our colleagues, in responding to the theory, challenged us with cases that clearly gave us reason for concern. One of the early and most frequent examples raised by our audience was a sexual harassment example. Another involved a physical threat. We should have anticipated it. After all, we told them that the key to recognition of these moments was a situation that was affectively hot, weird, uncomfortable, and difficult. This fits perfectly their experience of a sexually inappropriate comment. Their point was that they could not follow our advice to this kind of comment because it would be dangerous to respond in a genuine and personal manner to sexual harassment. They clarified that the moments of which they spoke with concern were not merely naively inappropriate, as in the case of a student with a crush on his teacher. They were referring to power moves meant to control the teacher. All of the speakers who voiced these concerns were women who were speaking from personal experience and obviously deeply troubled by them.

These examples are from relationships in which the mutual goals have changed to render them outside the teacher-student range of mutual influence. Threats of harm or attempts at sexual involvement by either participant are not, by definition, part of the educational relationship. It may be true that a sequence of moments of meeting, or now moments, could be identified leading up to these phenomena; however, the improvisational freedom to respond with authenticity no longer applies when the relationship has altered in these ways. On the contrary, it now behooves the teacher to recognize the altered state of the student, be it sexual arousal or destructive rage, and respond in very measured and specific ways that set limits and protect the participants' personal and physical integrity. The theory we are offering here has nothing to contribute to the strategies necessary to manage these emergent and potentially dangerous situations. We learned from our workshop experience how 
important it is to clarify this limitation and to clearly delineate our focus on the well-functioning educational dyad.

The teacher-learner relationship is set apart from other kinds of relationships such as romantic relationships and abusive relationships by the unique set of obligations and expectations that define it. Although teacher-learner relationships can be accommodating of growth and change they also presume certain ground rules that are not open for negotiation, such as safety and appropriate boundaries.

A useful analogy might be one of two of musicians jamming with each other. They both understand that they must play together in a certain way, each respecting the other's role and contribution to the music. Either one of them can then take the playing in a new direction, establishing a new theme or groove. But the same principles of cooperatively playing a piece of music together would still exist. However, if one musician decided to drown out the other on purpose or somehow ruin their contribution to the music, the basic ground rules would be broken and the musicians might not be able to play together any more. In a teacher-student relationship, moving along (Sterns et al., 1998) occurs much like these musicians jamming. Each can take the relationship in a new direction, within certain limits. A student who threatens his teacher by failing to play along with the Socratic method is merely challenging a variation of the expectations making up the relationship. But a student who threatens his teacher with physical harm is going much further. He or she is changing the very nature of the relationship to one that is no longer cooperative and mutually respectful - from an educational one to an abusive or sexual one.

We have suggested exercises aimed at helping teachers learn how to respond more effectively to now moments that challenge the teacher-learner relationship. But for other, more fundamental challenges to the interpersonal relationship, different responses may be warranted. Even an effective, authentic teacher would handle differently a challenge to the teacher-learner relationship such as, "You don't really care about me," versus a challenge to the basic safety or stability of the interpersonal relationship such as, "You'd better watch your back when you leave your office tonight. ${ }^{.}$

There is a sense in which the teacher can say, with respect to the first case, that the student was a very challenging student to teach but the student was not uncivil, rude, or violent. The teacher responding to the second case may say that the student was way beyond a teaching-learning contract; he or she was not even civil. There was no way this student should be in this university. There is a lot of writing coming out these days on uncivil behavior. It is a big 
issue because it frightens teachers. It is not surprising that teachers want to use our microanalysis to understand incivility and to learn ways to cope with it. Although this need is understandable, it is probably not a useful application of these proposals.

We are not discussing strategies for dealing with inappropriate student behavior. Our analysis is focused on the ability to de-center from business as usual and to get enough psychological distance from our performances that we can recognize an unusual interpersonal situation when it occurs within the context of the teacher-student relationship. What we are arguing is that there are different kinds of unusual situations. It is possible for someone to respond in a personal, constructive manner to one type of now moment, while at the same time refusing to do so for another now moment because he or she recognizes the latter as beyond the allowable zone for teacher-student relationships. The former challenges the techniques that we are using but not to the normal civility that is accorded another person in our society. The latter, like the sexual examples given by some of the participants in our workshops, were clearly beyond the acceptable teacher-student relationship in our society. We agree with Palmer (1998) that fear is part of good teaching, but not fear for your life.

\section{Conclusion}

In this chapter we described how the theory underlying now moments might be usefully applied to teacher-student relationships and we suggested three strategies for training teachers in responding to now moments more effectively. We hope that we have opened an important discussion. However, there is very little evidence, as yet, to support our suggestions. Early in our investigation of this topic, experienced teachers, who were as enthusiastic about the theory as we were, encouraged us. They told us that the theory helped them understand some of their most troublesome teaching moments, ones that both confused and distressed them. They also found their new understanding to be quite unsettling. Some teachers literally gasped when they imagined how many now moments they might have missed. Teachers were eager to know how they could use the theory to become more aware of now moments and to respond to them more effectively. Therefore, in preparation to conduct workshops on this topic, we searched the literature for strategies that might help teachers. Participants with experience in improvisational theater and mindfulness agreed that these training methods were particularly suited to the task.

The next step, certainly, is to study the phenomenon in an educational setting. We must attempt to document, in a detailed descriptive fashion, now 
moments occurring in typical educational scttings. Are they common occurrences or rare? How frequently are they missed either by the teacher or the learner? And we must attempt to measure the effect of knowledge of the theory or skills training on success in addressing such moments. Does knowledge of the theory itself or skills acquired in any of the training methods confer any benefit? We welcome any colleagues who are interested in joining us in this exciting phase.

\section{REFERENCES}

Brookfield, S. D. (1990). The skillful teacher: On technique, trust, and responsiveness in the classroom. San Francisco, CA: Jossey-Bass.

Chickering, A. W., \& Reisser, L. (1993). Education and identity. San Francisco, CA: Jossey-Bass.

hooks, b. (1994). Teaching to transgress: Education as she practice of freedom. New York, NY: Routledge.

Irby, D. M. (1994). What clinical teachers in medicine need to know. Academic Medicine, 69, 333-342.

Kabat-Zinn, J. (1990). Full catastrophe living: Using the wisdom of your body and mind to face stress, pain, and illness. New York, NY: Delta Press.

Lowman, J. (1984). Mastering the techniques of teaching. San Francisco, CA: JosseyBass.

Palmer, P. J. (1998). The courage to teach: Exploring the inner landscape of a teacher's life. San Francisco, CA: Jossey-Bass.

Stern, D. N., Sander, L. W., Nahum, J. P., Harrison, A. M., Lyons-Ruth, K., Morgan, A. C., Bruschwciler-Stern, N., \& Tronick, E. Z. (1998). Non-interpretive mechanisms in psychoanalytic therapy: The "something more" than interpretation. International Journal of Psycho-Analysis, 79, 903-921.

Teasdale, J. D., Segal, Z., \& Williams, J. M. G. (1995). How does cognitive therapy prevent depressive relapse and why should attentional control (mindfulness) training help? Behavior Research and Therapy, 33(1), 25-39.

Tiberius, R. G., \& Billson, J. M (1991). The social context of teaching and learning. In R. J. Menges \& M. Svinicki (Eds.) College teaching: From theory to practice (pp. 67-86). New Directions for Teaching and Learning. No. 45. San Francisco, CA: Jossey-Bass. 


\title{
Contact:
}

Richard G. Tiberius

University of Toronto Faculty of Medicine

Centre For Research in Education at the University Health Network

200 Elizabeth Street

1ES 583, Toronto, Ontario M5G 2C4 Canada

Voice (416) 340-4194,

Fax (416) 340-3792

Email r.tiberius@utoronto.ca

\section{John Teshima}

Department of Psychiatry, University of Toronto

Sunnybrook and Women's College Health Sciences Centre

2075 Bayview Avenue, F-Wing

Toronto, Ontario M4N 3M5 Canada

Voice (416) 480-6100 ext. 3077

Fax (416) 480-6818

Email john.teshima@utoronto.ca

\author{
Alan R. Kindler \\ Department of Psychiatry and St. Michael's Hospital \\ University of Toronto \\ Toronto, Ontario M5G 2C4 Canada \\ Voice (416) 923-8868 \\ Fax (416) 920-2483 \\ Email kindler@istar.ca
}

Richard G. Tiberius has a PhD in Applied Psychology from the Ontario Institute for Studies in Education/University of Toronto. He holds the position of professor in the Department of Psychiatry and the Centre for Research in Education where he collaborates with medical faculty in designing and conducting educational research and faculty development activities. His scholarly work and consulting practice focuses on the improvement of the teaching and learning process, especially the role of the teacherstudent relationship in learning. He has authored numerous journal articles, book chapters, and books in United States, Canadian, and British journals, and has conducted workshops and lectured throughout North America and Europe.

John Teshima completed medical school and his psychiatry residency at the University of Toronto. He is currently completing an M.Ed. at the Ontario Institute for Studies in Education/University of Toronto. He is a staff psychiatrist at Sunnybrook and Women's College Health Sciences Centre, where he is the undergraduate education coordinator for psychiatry. He is a lecturer in the University of Toronto's Department of Psychiatry. He is also the education coordinator for a telehealth project that 
provides children's mental health services to underserviced communities across Ontario. His main educational interests are in undergraduate medical education and also in continuing education for health professionals.

Alan R. Kindler is a Training and Supervising Analyst with the Toronto Institute of Psychoanalysis and past president of the Toronto Psychoanalytic Society. He is an Assistant Professor of Psychiatry at the University of Toronto, a staff psychiatrist at the Wellesley and St. Michael's Hospitals and is on the faculties of the Toronto Institure of Contemporary Psychoanalysis, the Toronto Child Psychotherapy Program, and the Advanced Training Program in Psychoanalytic Psychotherapy. He is in private analytic practice and has a special interest in self psychology. He is on the International Council for Psychoanalytic Self Psychology and a board and faculty member of the Institute for the Advancement of Self Psychology in Toronto. His recent publications include an edition of Psychoanalytic Inquiry on Psychoanalytic Supervision (co-edited with Dr. Joshua Levy) and "Optimal Responsiveness and Psychoanalytic Supervision" (in $O_{p}$ timal Responsiveness: How Therapists Heal Their Patients, edited by H. Bacal, 1997). 